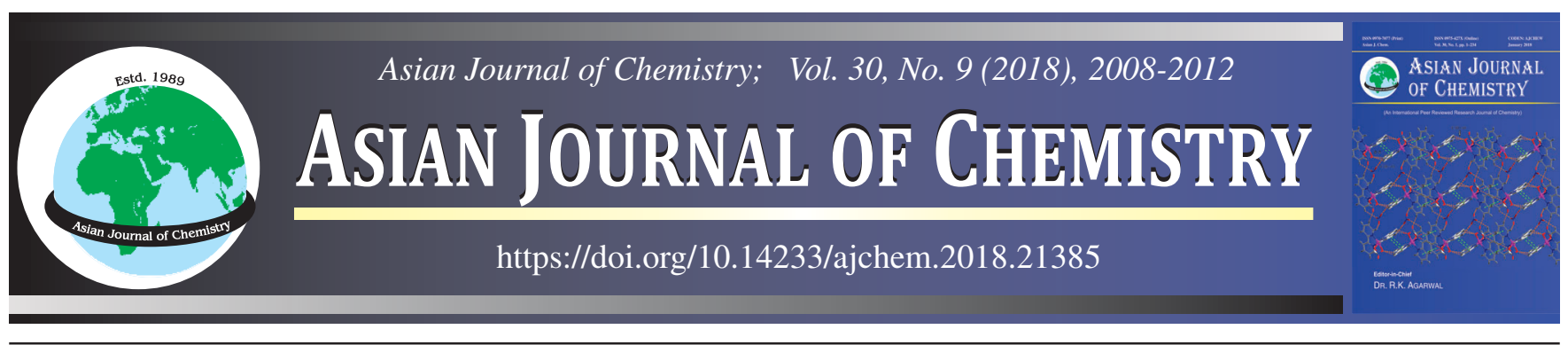

\title{
Viscosity and Speed of Sound Studies of Binary Liquid Mixtures of Formamide with N,N-Dimethylaniline at Different Temperatures
}

Nagarjuna Ayachithula, Babu Shaik*, Govinda Rao Konkyana and Kalimulla Thummaluru

Department of Physics, Koneru Lakshmaiah Education Foundation, Vaddeswaram, Guntur-522 502, India

*Corresponding authors: E-mail: babu.computers@gmail.com

Received: 2 February 2018;

Accepted: 31 March 2018;

Published online: 31 July 2018;

AJC-19011

Theoretical values of speed of sound in binary liquid mixtures of fomamide with $\mathrm{N}, \mathrm{N}$-dimethylaniline have been evaluated at 303.15 , 308.15 and $313.15 \mathrm{~K}$. The experimentally determined values of speed of sound have been used to check the applicability of different speed of sound models of Nomoto (NOM), impedance (IMP), ideal mixing relation (IMR), Vandael and Vangeel (VDV), Junjie (JUN) and Rao's specific velocity (RAO) relation. The validity of these theories was checked by applying chi-square test $(\chi)$ for goodness of fit and by calculating the average percentage error. Further viscosity data have been used to test the applicability of standard viscosity models of Hind, Grunberg and Nissan, Katti and Chaudhri, Wiki, Tamura and Kurata, after that corresponding interaction terms and standard deviation $(\sigma)$ of these theories are calculated at various temperatures for the binary liquid systems. The results are interpreted in terms of molecular interaction between the components of the binary mixtures.

Keywords: Speed of sound, Formamide, N,N-Dimethylaniline, Viscosity,

\section{INTRODUCTION}

In chemical process industries, materials are normally handled in fluid form and as a consequence the physical, chemical and transport properties of fluids, assume importance. Thus, data on some of the properties associated with the liquids and liquid mixtures like ultrasonic velocity, viscosity and density invention extensive application in solution theory models and molecular dynamics [1,2]. The classification of mixtures through their thermodynamic and transport properties is substantial from the foremost viewpoint of understand their mixing behaviour. The impetus of the present investigation is to compare the experimentally determined speed of sound, viscosity and density with the computed values using different analytical models and empirical relations [1-4].

Such results were obtained by earlier workers [5-8], an increasing variety of research techniques are being employed to get an insight into the molecular behaviour of liquids. In the present stage of development, ultrasonic techniques are yielding fruitful results comparable with those of other methods in the elucidation of molecular mechanisms. Measurement of sound velocity has been used for many years in connection with the determination of elastic and thermodynamic properties of gases, liquids and solids. Intimate relations between the values of sound velocity and chemical or structural characteristics of molecules of liquids or liquid mixtures have been found. This gives sound velocity of the primary quantity in the molecular theory of liquids $[5,6]$. Theoretical evaluation of ultrasonic velocity in binary liquid mixtures and its comparison with the experimental values reflects the molecular interaction in liquid mixtures, which is very useful to build comprehensive theoretical models for liquids. Several researchers $[1,2,7,8]$ carried out investigations on liquid mixtures and correlated the experimental results of ultrasonic velocity with the theoretical relations of Nomoto (NOM), impedance (IMP), ideal mixing relation (IMR), Vandael and Vangeel (VDV), Junjie (JUN) and Rao's specific velocity (RAO) relation [2]. The validity of these theories was checked by applying chi-square test $(\chi)$ for goodness of fit and by calculating the average percentage error (APE) $[2,6]$. Further, the mixture viscosities were correlated using Hind, Grunberg and Nissan, Katti and Chawdhry, Tamura \& Kurata, equations to test their relative applicability with standard deviation $(\sigma)[2,6]$ for the binary mixture of formamide with $\mathrm{N}, \mathrm{N}-$ dimethylaniline at different mole fractions [9-11]. The results

This is an open access journal, and articles are distributed under the terms of the Creative Commons Attribution-NonCommercial 4.0 International (CC BY-NC 4.0) License, which allows others to copy and redistribute the material in any medium or format, remix, transform, and build upon the material, as long as appropriate credit is given and the new creations are licensed under the identical terms. 
are explained and discussed in terms of molecular interactions present in the investigated systems.

\section{EXPERIMENTAL}

The ultrasonic velocities were measured at 303.15 to 313.15 $\mathrm{K}$ using ultrasonic interferometer (M/s Mittal Enterprises, India) operating at a frequency of $2 \mathrm{MHz}$ with an accuracy of $\pm 0.1 \mathrm{~m} / \mathrm{s}$ for the compounds of formamide with N,N-dimethylaniline. The densities were measured by using specific gravity bottle method, while viscosity were measured by using Ostwald's viscometer by the standard procedure.

The following empirical relations are used for the prediction of ultrasonic velocity in the binary liquid mixtures.

\section{Ultrasonic theories}

Nomoto's relation:

$$
\mathrm{U}_{\mathrm{NOM}}=\left[\mathrm{X}_{1} \mathrm{R}_{1}+\mathrm{X}_{2} \mathrm{R}_{2} / \mathrm{X}_{1} \mathrm{~V}_{1}+\mathrm{X}_{2} \mathrm{~V}_{2}\right]
$$

Ideal mixture relation:

$\mathrm{U}_{\mathrm{IMR}}=\left[1 / \mathrm{X}_{1} \mathrm{~m}_{1}+\mathrm{X}_{2} \mathrm{~m}_{2}\right]^{1 / 2}\left[\mathrm{X}_{1} / \mathrm{m}_{1} \mathrm{U}_{1}^{2}+\mathrm{X}_{2} / \mathrm{m}_{2} \mathrm{U}_{2}^{2}\right]^{-1 / 2}$

Junjie's method:

$$
\begin{aligned}
\mathrm{U}_{\mathrm{JM}}= & {\left[\mathrm{X}_{1} \mathrm{~V}_{1}+\mathrm{X}_{2} \mathrm{~V}_{2} /\left(\mathrm{X}_{1} \mathrm{~m}_{1}+\mathrm{X}_{2} \mathrm{~m}_{2}\right)^{1 / 2}\right]\left[\mathrm{X}_{1} \mathrm{~V}_{1} / \mathrm{d}_{1} \mathrm{U}_{1}^{2}+\right.} \\
& \left.\mathrm{X}_{2} \mathrm{~V}_{2} / \mathrm{d}_{2} \mathrm{U}_{2}^{2}\right]^{-1 / 2}
\end{aligned}
$$

Imedance relation:

$$
\mathrm{U}_{\mathrm{IMP}}=\mathrm{X}_{1} \mathrm{Z}_{1}+\mathrm{X}_{2} \mathrm{Z}_{2} / \mathrm{X}_{1} \rho_{1}+\mathrm{X}_{2} \rho_{2}
$$

Vandael and Vangeel relation:

$$
\mathrm{U}_{\mathrm{VDV}}=\left[1 / \mathrm{X}_{1} \mathrm{~m}_{1}+\mathrm{X}_{2} \mathrm{~m}_{2}\right] 1 / 2\left[\mathrm{X}_{1} / \mathrm{m}_{1} \mathrm{U}_{1}^{2}+\mathrm{X}_{2} / \mathrm{m}_{2} \mathrm{U}_{2}^{2}\right]^{-1 / 2}
$$

Rao's relation:

$$
\mathrm{U}_{\mathrm{R}}=(\mathrm{R} / \mathrm{V})^{3}
$$

The validity of the theories is checked by applying Chisquare test and by calculating average percentage error (APE), the relations as follows:

$$
\begin{gathered}
\operatorname{APE}(\%)=\left[\left(1 /(\mathrm{n}) \Sigma 100\left(\mathrm{U}_{\exp }-\mathrm{U}_{\text {cal }}\right) / \mathrm{U}_{\text {exp }}\right)\right] \times 100 \\
\text { Chi-square }(\chi)=\sum_{\mathrm{i}}^{\mathrm{n}}\left(\frac{\left(\mathrm{U}_{\text {exp }}-\mathrm{U}_{\text {cal }}\right)^{2}}{\mathrm{U}_{\text {cal }}}\right)
\end{gathered}
$$

\section{Viscosity theories}

Hind proposed the equation:

$$
\eta=\mathrm{x}_{1}{ }^{2} \eta_{1}+\mathrm{x}_{2}^{2} \eta_{2}+2 \mathrm{x}_{1} \mathrm{x}_{2} \mathrm{H}_{12}
$$

Katti and Chaudhri derived the equation:

$$
\ln \eta \mathrm{V}=\mathrm{x}_{1} \ln \eta_{1} \mathrm{~V}_{1}+\mathrm{x}_{2} \ln \eta_{2} \mathrm{~V}_{2}+\mathrm{x}_{1} \mathrm{x}_{2} \mathrm{Wvis} / \mathrm{RT}
$$

Wiki expression is:

$$
\log \eta_{\mathrm{m}}=\mathrm{x}_{1}{ }^{2} \log \eta_{1}+\mathrm{x}_{2}{ }^{2} \log \eta_{2}+2 \mathrm{x}_{1} \mathrm{x}_{2} \log \eta_{12}
$$

Gruenberg-Nissan provided the equation:

$$
\ln \eta_{12}=x_{1} \ln \eta_{1}+x_{2} \ln \eta_{2}+x_{1} x_{2} G_{12}
$$

Tamura and Kurata gave the equation:

$$
\eta_{\mathrm{m}}=\mathrm{x}_{1} \eta_{1} \phi_{1}+\mathrm{x}_{2} \eta_{2} \phi_{2}+2\left(\mathrm{x}_{1} \mathrm{x}_{2} \phi_{1} \phi_{2}\right)^{1 / 2} \mathrm{~T}_{12}
$$

The standard deviation:

$$
\sigma=\left[\left(1 /(\mathrm{n}-\mathrm{K}) \Sigma 100\left(\eta_{\exp }-\eta_{\text {cal }}\right) / \eta_{\exp }\right)^{2}\right]^{1 / 2}
$$

\section{RESULTS AND DISCUSSION}

The comparison of experimental values of densities $(\rho)$, viscosities $(\eta)$ and ultrasonic velocities (u) with the literature values are given in Table-1. The experimental values of ultrasonic velocities along with the theoretically evaluated values by using various theories in the binary liquid mixtures of formamide with $\mathrm{N}, \mathrm{N}$-dimethylaniline at different temperatures $(\mathrm{T}=$ $303.15,308.15$ and $313.15 \mathrm{~K}$ ) are given in Table-2 and the average percentage error (APE) and chi square test $(\chi)$ also included in the Tables.

The average percentage error values are small. On comparison, the Nomoto's relation and impedance relation are found to provide some valuable information on the speed of sound values in these mixtures. The predictive abilities of various speeds of sound theories depend upon the strength of interaction prevailing in a system [2,7]. The extent of deviation may be attributed to the assumptions made in these theories for the non-polar-polar and non-polar-non-polar interaction between the molecules $[12,13]$. The chi-square value and average percentage error value is minimum for Nomoto's relation and Junjie's method than those obtained by other theories. An important reason for deviation from experimental values of speed of sound is that the molecular association effects are not taken into account in these theories [1,2]. Thus the observed deviation of theoretical values of speed of sound from the experimental

\begin{tabular}{|c|c|c|c|c|c|c|c|}
\hline \multirow{2}{*}{ Liquid } & \multirow{2}{*}{ Temp. (K) } & \multicolumn{2}{|c|}{ Density $(\rho)\left(\mathrm{kg} \mathrm{m}^{-3}\right)$} & \multicolumn{2}{|c|}{ Viscosity $(\eta)\left(\mathrm{kg} \mathrm{m}^{1} \mathrm{~s}^{-1}\right)$} & \multicolumn{2}{|c|}{ Speed of sound $(\mathrm{U})\left(\mathrm{m} \mathrm{s}^{-1}\right)$} \\
\hline & & Literature & Experimental & Literature & Experimental & Literature & Experimental \\
\hline \multirow{3}{*}{ Formamide } & 303.15 & $1.1247^{\mathrm{a}}$ & 1.1281 & $2.80^{\mathrm{b}}$ & 2.83 & $1585.4^{\mathrm{c}}$ & 1585.0 \\
\hline & 308.15 & $1.1205^{\mathrm{a}}$ & 1.1208 & $2.50^{\mathrm{b}}$ & 2.59 & $1580.6^{c}$ & 1580.0 \\
\hline & 313.15 & $1.1164^{\mathrm{a}}$ & 1.1110 & $2.20^{\mathrm{b}}$ & 2.29 & $1572.0^{\mathrm{c}}$ & 1572.0 \\
\hline \multirow{3}{*}{$\begin{array}{l}\mathrm{N}-\mathrm{N} \text { dimethyl } \\
\text { aniline }\end{array}$} & 303.15 & $0.9481^{\mathrm{d}}$ & 0.9453 & $1.173^{\mathrm{e}}$ & 1.171 & $1470.5^{f}$ & 1470.0 \\
\hline & 308.15 & $0.9439^{d}$ & 0.9431 & $1.078^{\mathrm{e}}$ & 1.041 & $1453.4^{\mathrm{f}}$ & 1453.4 \\
\hline & 313.15 & $0.9397^{\mathrm{d}}$ & 0.9360 & $0.989^{\mathrm{e}}$ & 0.989 & $1435.2^{f}$ & 1435.2 \\
\hline
\end{tabular}
values shows that the molecular interaction is taking place between the unlike molecules in the liquid mixtures [14]. Hence, the observed deviation shows that the molecular interaction is taking place between the unlike molecules in the liquid mixture. This suggests the existence of strong tendency for the association between component molecules as a result of hydrogen bonding.

The comparison of viscosity theories at different temperatures ( 303.15 to $313.15 \mathrm{~K}$ ) are observed by using of interaction parameter and standard deviation $(\sigma)$ is given in Table-3. Semi-

TABLE-1

COMPARISON OF EXPERIMENTAL DENSITIES $(\rho)$, VISCOSITIES $(\eta)$ AND SPEED OF SOUND (U) OF PURE LIQUIDS WITH LITERATURE VALUES 
TABLE-2

SPEED OF SOUND THEORIES FOR THE BINARY MIXTURES OF FORMAMIDE WITH N,N-DIMETHYL ANILINE AT 303.15 K, 308.15K AND 313.15 K

\begin{tabular}{|c|c|c|c|c|c|c|c|c|c|}
\hline $\mathrm{x}_{1}$ & $\begin{array}{c}\rho \\
\left(\mathrm{kg} \mathrm{m}^{-3}\right)\end{array}$ & $\begin{array}{c}\mathrm{U}_{\mathrm{EXP}} \\
\left(\mathrm{m} \mathrm{s}^{-1}\right)\end{array}$ & $\begin{array}{c}\eta \\
\left(\mathrm{kg} \mathrm{m}^{1} \mathrm{~s}^{-1}\right)\end{array}$ & $\begin{array}{c}\mathrm{U}_{\mathrm{NOM}} \\
\left(\mathrm{m} \mathrm{s}^{-1}\right)\end{array}$ & $\begin{array}{c}\mathrm{U}_{\mathrm{IMR}} \\
\left(\mathrm{m} \mathrm{s}^{-1}\right)\end{array}$ & $\begin{array}{c}\mathrm{U}_{\mathrm{IMP}} \\
\left(\mathrm{m} \mathrm{s}^{-1}\right)\end{array}$ & $\begin{array}{c}\mathrm{U}_{\mathrm{JM}} \\
\left(\mathrm{m} \mathrm{s}^{-1}\right)\end{array}$ & $\begin{array}{c}\mathrm{U}_{\mathrm{VDV}} \\
\left(\mathrm{m} \mathrm{s}^{-1}\right)\end{array}$ & $\begin{array}{c}\mathrm{U}_{\mathrm{R}} \\
\left(\mathrm{m} \mathrm{s}^{-1}\right)\end{array}$ \\
\hline \multicolumn{10}{|c|}{$303.18 \mathrm{~K}$} \\
\hline 0.0000 & 1.1281 & 1585.0 & 2.8316 & 1585.0 & 1585.0 & 1585.0 & 1585.0 & 1585.00 & 1585.0 \\
\hline 0.2629 & 1.1224 & 1579.0 & 2.6323 & 1568.9 & 1389.4 & 1558.5 & 1562.0 & 1389.40 & 1652.7 \\
\hline 0.4453 & 1.1105 & 1570.4 & 2.4576 & 1554.2 & 1338.6 & 1538.8 & 1543.2 & 1338.58 & 1689.3 \\
\hline 0.5791 & 1.1015 & 1565.8 & 2.2638 & 1540.7 & 1330.3 & 1523.4 & 1527.7 & 1330.35 & 1734.8 \\
\hline 0.6816 & 1.0901 & 1558.6 & 2.0326 & 1528.2 & 1339.3 & 1511.2 & 1514.8 & 1339.34 & 1764.8 \\
\hline 0.7625 & 1.0686 & 1542.8 & 1.8949 & 1516.7 & 1356.3 & 1501.2 & 1503.9 & 1356.30 & 1740.5 \\
\hline 0.8281 & 1.0396 & 1533.0 & 1.7661 & 1506.0 & 1377.2 & 1492.8 & 1494.7 & 1377.15 & 1674.2 \\
\hline 0.8822 & 0.9982 & 1518.6 & 1.5397 & 1496.1 & 1399.8 & 1485.8 & 1487.0 & 1399.79 & 1544.9 \\
\hline 0.9278 & 0.9772 & 1501.6 & 1.3687 & 1486.8 & 1423.2 & 1479.8 & 1480.4 & 1423.23 & 1508.1 \\
\hline 0.9666 & 0.9627 & 1490.4 & 1.2847 & 1478.1 & 1446.8 & 1474.6 & 1474.8 & 1446.75 & 1497.6 \\
\hline 1.0000 & 0.9453 & 1470.0 & 1.1712 & 1470.0 & 1470.0 & 1470.0 & 1470.0 & 1470.00 & 1470.0 \\
\hline \multicolumn{4}{|c|}{ Average percentage error (APE) } & 0.0042 & 0.0302 & 0.0067 & 0.0063 & 0.0302 & -0.0320 \\
\hline \multicolumn{4}{|c|}{ Chi square test $(\chi)$} & 0.4489 & 25.6448 & 1.1549 & 1.0060 & 25.6448 & 22.4671 \\
\hline \multicolumn{10}{|c|}{$308.15 \mathrm{~K}$} \\
\hline 0.0000 & 1.1208 & 1580.0 & 2.5990 & 1580.0 & 1580.0 & 1580.0 & 1580.0 & 1580.00 & 1580.0 \\
\hline 0.1461 & 1.1106 & 1579.0 & 2.5320 & 1562.3 & 1379.0 & 1550.8 & 1555.1 & 1379.02 & 1622.9 \\
\hline 0.2780 & 1.0727 & 1558.0 & 2.3460 & 1546.1 & 1326.5 & 1529.0 & 1534.6 & 1326.54 & 1539.4 \\
\hline 0.3977 & 1.0519 & 1537.6 & 2.1859 & 1531.3 & 1317.3 & 1512.1 & 1517.7 & 1317.35 & 1523.9 \\
\hline 0.5066 & 1.0264 & 1526.4 & 2.0018 & 1517.6 & 1325.6 & 1498.6 & 1503.5 & 1325.62 & 1482.6 \\
\hline 0.6064 & 1.0053 & 1515.2 & 1.8682 & 1504.9 & 1342.0 & 1487.6 & 1491.5 & 1341.97 & 1455.5 \\
\hline 0.6979 & 0.9816 & 1509.0 & 1.7456 & 1493.1 & 1362.3 & 1478.5 & 1481.3 & 1362.29 & 1412.7 \\
\hline 0.7823 & 0.9734 & 1492.2 & 1.6431 & 1482.1 & 1384.4 & 1470.7 & 1472.7 & 1384.44 & 1433.3 \\
\hline 0.8604 & 0.9528 & 1481.6 & 1.4499 & 1471.9 & 1407.4 & 1464.1 & 1465.3 & 1407.43 & 1396.3 \\
\hline 0.9327 & 0.9480 & 1472.4 & 1.2908 & 1462.3 & 1430.5 & 1458.4 & 1458.9 & 1430.54 & 1426.0 \\
\hline 1.0000 & 0.9431 & 1453.4 & 1.0417 & 1453.4 & 1453.4 & 1453.4 & 1453.4 & 1453.40 & 1453.4 \\
\hline \multicolumn{4}{|c|}{ Average percentage error (APE) } & 0.0017 & 0.0286 & 0.0046 & 0.0039 & 0.0286 & 0.0099 \\
\hline \multicolumn{4}{|c|}{ Chi square test $(\chi)$} & 0.0710 & 22.3606 & 0.5120 & 0.3769 & 22.3606 & 2.4528 \\
\hline \multicolumn{10}{|c|}{$313.15 \mathrm{~K}$} \\
\hline 0.0000 & 1.1110 & 1572.8 & 2.2958 & 1572.8 & 1572.8 & 1572.8 & 1572.8 & 1572.80 & 1572.8 \\
\hline 0.1461 & 1.1050 & 1568.8 & 2.1626 & 1553.6 & 1366.9 & 1541.0 & 1545.8 & 1366.87 & 1631.2 \\
\hline 0.2780 & 1.0962 & 1557.8 & 2.0767 & 1536.0 & 1312.9 & 1517.3 & 1523.7 & 1312.88 & 1674.0 \\
\hline 0.3977 & 1.0519 & 1531.8 & 1.9689 & 1519.8 & 1302.8 & 1498.9 & 1505.3 & 1302.79 & 1550.7 \\
\hline 0.5066 & 1.0259 & 1525.8 & 1.8903 & 1504.9 & 1310.4 & 1484.3 & 1489.9 & 1310.36 & 1504.6 \\
\hline 0.6064 & 1.0057 & 1509.4 & 1.7781 & 1491.1 & 1326.1 & 1472.3 & 1476.9 & 1326.11 & 1479.2 \\
\hline 0.6979 & 0.9914 & 1497.8 & 1.6041 & 1478.3 & 1345.9 & 1462.4 & 1465.8 & 1345.89 & 1475.8 \\
\hline 0.7823 & 0.9728 & 1482.6 & 1.4576 & 1466.4 & 1367.5 & 1454.0 & 1456.4 & 1367.55 & 1449.2 \\
\hline 0.8604 & 0.9648 & 1477.6 & 1.3389 & 1455.3 & 1390.1 & 1446.8 & 1448.3 & 1390.07 & 1467.0 \\
\hline 0.9327 & 0.9487 & 1452.8 & 1.2253 & 1444.9 & 1412.8 & 1440.6 & 1441.3 & 1412.75 & 1444.9 \\
\hline 1.0000 & 0.9360 & 1435.2 & 0.9890 & 1435.2 & 1435.2 & 1435.2 & 1435.2 & 1435.20 & 1435.2 \\
\hline \multicolumn{4}{|c|}{ Average percentage error (APE) } & 0.0030 & 0.0304 & 0.0061 & 0.0054 & 0.0304 & 0.0050 \\
\hline \multicolumn{4}{|c|}{ Chi square test $(\chi)$} & 0.2249 & 25.3327 & 0.9328 & 0.7151 & 25.3327 & 0.6164 \\
\hline
\end{tabular}

TABLE-3

VISCOSITY THEORIES FOR THE BINARY MIXTURES OF FORMAMIDE WITH N,N-DIMETHYLANILINE AT DIFFERENT TEMPERATURES

\begin{tabular}{clccccc}
\hline \multirow{2}{*}{ Temp. $(\mathrm{K})$} & & $\begin{array}{c}\text { Hind } \\
\left(\mathrm{H}_{12}\right)\end{array}$ & $\begin{array}{c}\text { Grunberg \& Nissan } \\
\left(\mathrm{G}_{12}\right)\end{array}$ & $\begin{array}{c}\text { Wiki } \\
\left(\log \eta_{12}\right)\end{array}$ & $\begin{array}{c}\text { Katti \& Chaudhary } \\
\left(\mathrm{W}_{\text {vis }} / \mathrm{RT}\right)\end{array}$ & $\begin{array}{c}\text { Tamura \& Kurata } \\
\left(\mathrm{T}_{12}\right)\end{array}$ \\
\hline \multirow{2}{*}{303.15} & Interaction parameter & 0.8302 & 0.8828 & 0.1917 & 1.6949 & 4.1407 \\
& Standard deviation $(\sigma)$ & 0.8346 & 0.6449 & 0.8346 & 1.0376 & 1.2323 \\
\hline \multirow{2}{*}{308.15} & Interaction parameter & 0.7790 & 0.9140 & 0.1990 & 1.2030 & 3.6490 \\
& Standard deviation $(\sigma)$ & 0.7150 & 1.4360 & 0.7150 & 0.0600 & 1.2350 \\
\hline \multirow{2}{*}{313.15} & Interaction parameter & 0.6530 & 0.8420 & 0.1830 & 5.5680 & 1.4410 \\
& Standard deviation $(\sigma)$ & 0.8710 & 1.4110 & 0.8710 & & 3.3530 \\
\end{tabular}

empirical relations have been used to represent the dependence of viscosity on concentration of components in binary liquid mixtures.
It is clear that Tamura and Kurata theory could not give accurate values compared to experimental values. These theories generally fail to predict accurately the values where strong inter- 
actions are supposed to exist due to the limitations and approximations incorporated in these theories. Various interaction parameters and their corresponding standard deviations of viscosity computed from different theories in liquid mixture of formamide with $\mathrm{N}, \mathrm{N}$-dimethylaniline at different temperatures $(303.15$, 308.15 and $313.15 \mathrm{~K}$ ). All the empirical models gave a reasonable fit in all these mixture. The estimated standard deviations are smaller in all cases indicating that the present mixture viscosities are well correlated by these viscosity models.

Plot the variation of evaluated speed of sound theories viz., Nomoto's (nom) relation, ideal mixing relation, impedance dependence relation, Rao's velocity relation ( $r$ ), Junjie's method (jm) for the formamide with N,N-dimethylaniline system at different temperatures against entire range of mole fraction $\left(\mathrm{X}_{1}\right)$. The variation of speed sound theories with respect to the entire mole fraction for formamide with N,N-dimethylaniline ranging from 0 to 1 at $303.15 \mathrm{~K}$ (Fig. 1), 308.15 K (Fig. 2) and $308.15 \mathrm{~K}$ (Fig. 3) are shown.

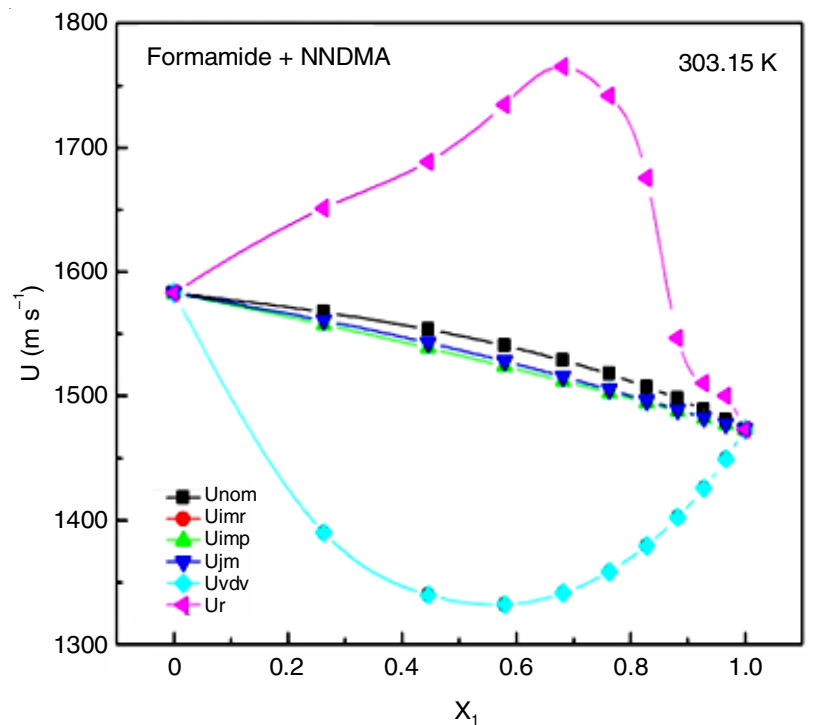

Fig. 1. Variation of speed of sound theories with respect to mole fraction at $303.15 \mathrm{~K}$

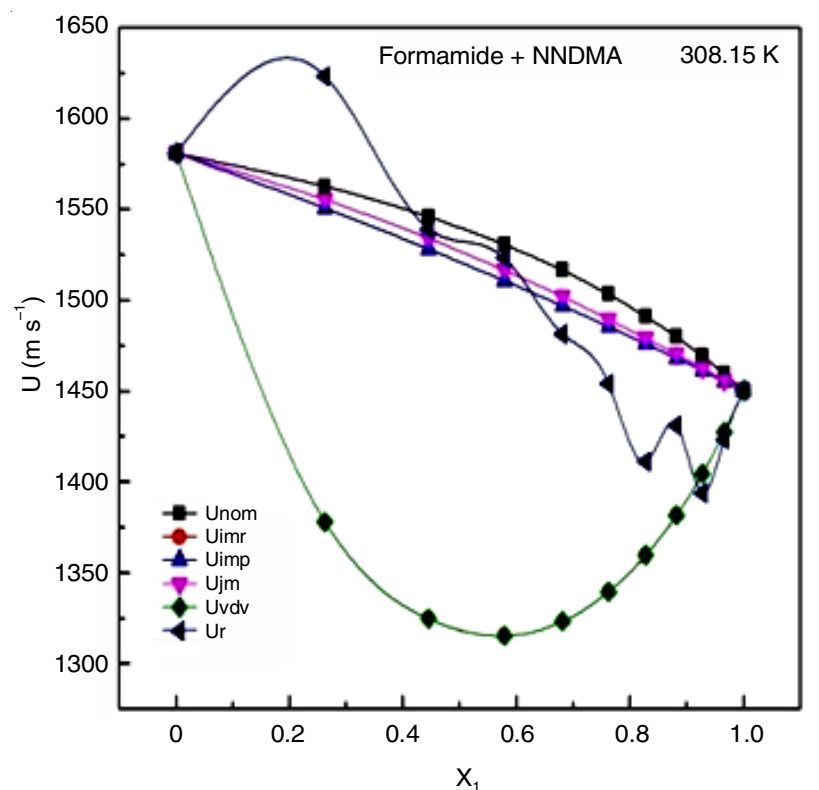

Fig. 2. Variation of speed of sound theories with respect to mole fraction at $308.15 \mathrm{~K}$

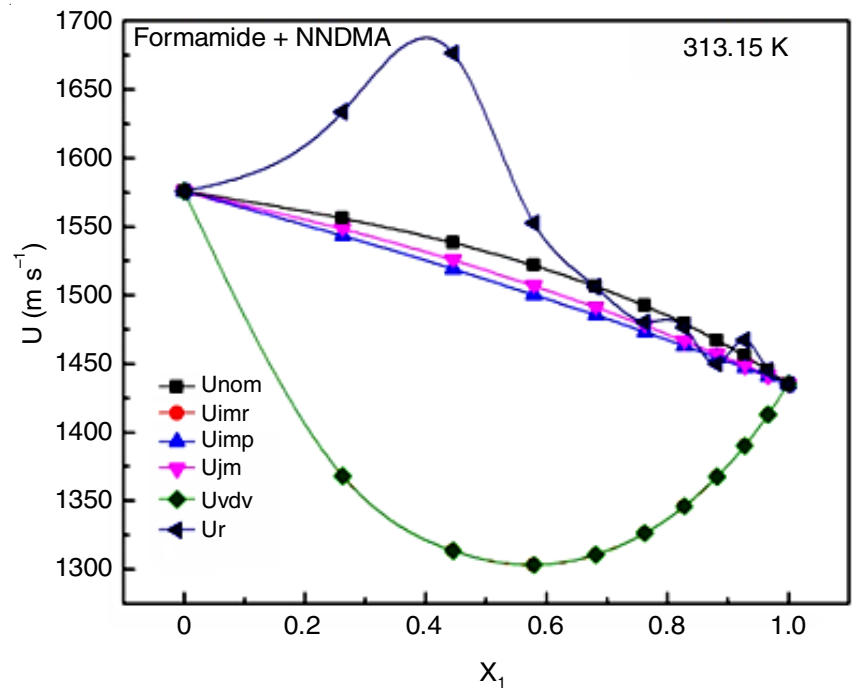

Fig. 3 Variation of speed of sound theories with respect to mole fraction at $313.15 \mathrm{~K}$

It gives an idea of extent of interaction taking place between molecules of the mixtures. The positive deviation for binary systems infers strong interactions between the components. The percentage of deviation in velocity is reflecting both negative and positive magnitudes, indicating non-ideal behaviour of liquid mixtures. The evaluated interaction parameters are positive for all the systems, indicating strong interactions between the mixing molecules. The dynamic viscosities of liquid mixtures have been calculated using several empirical relations viz., Hind, Grunberg and Nissan, Katti and Chaudhri, Wiki, Tamura and Kurata. Figs. 4-6 show the experimental values of viscosity for liquid mixture formamide with $\mathrm{N}, \mathrm{N}$-dimethylaniline at different temperatures $(303.15,308.15$ and $313.15 \mathrm{~K})$. The nonuniformity values of interaction parameter indicate the dominance of dispersion forces arising from the breakage of hydrogen

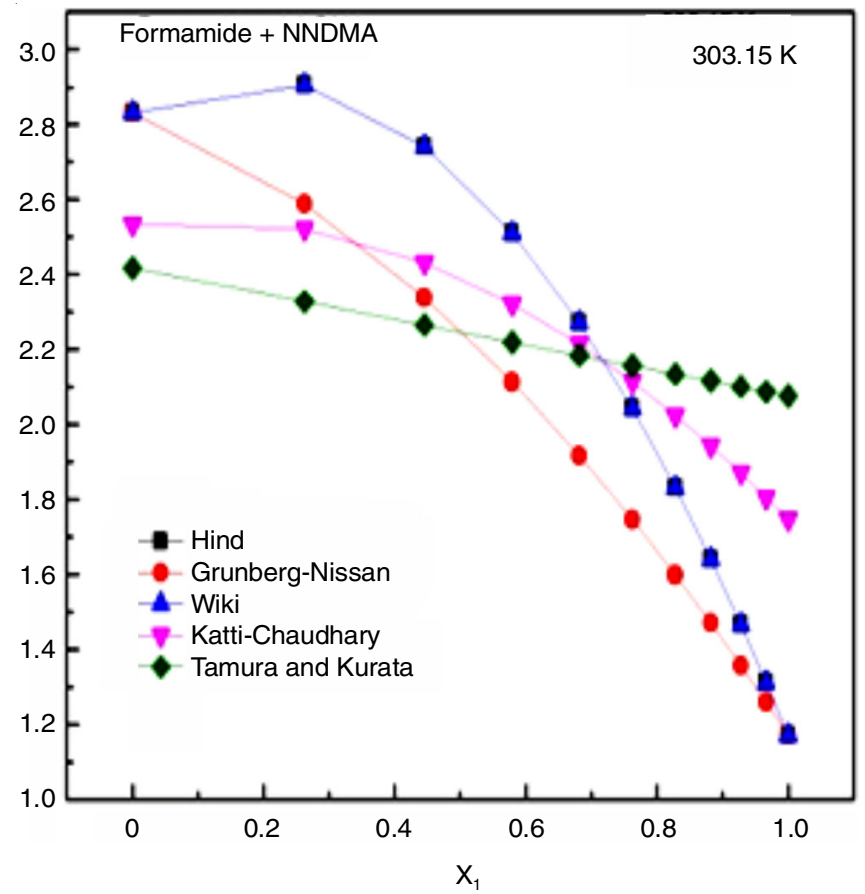

Fig. 4. Variation of viscosity theories with respect to mole fraction at $303.15 \mathrm{~K}$ 


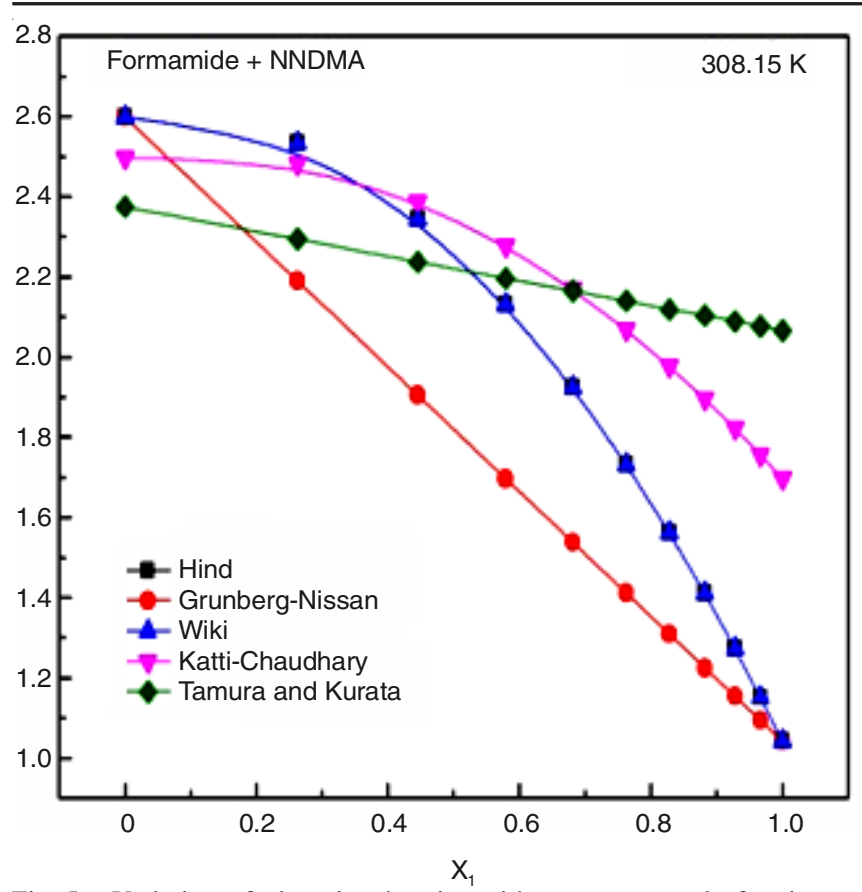

Fig. 5. Variation of viscosity theories with respect to mole fraction at $308.15 \mathrm{~K}$

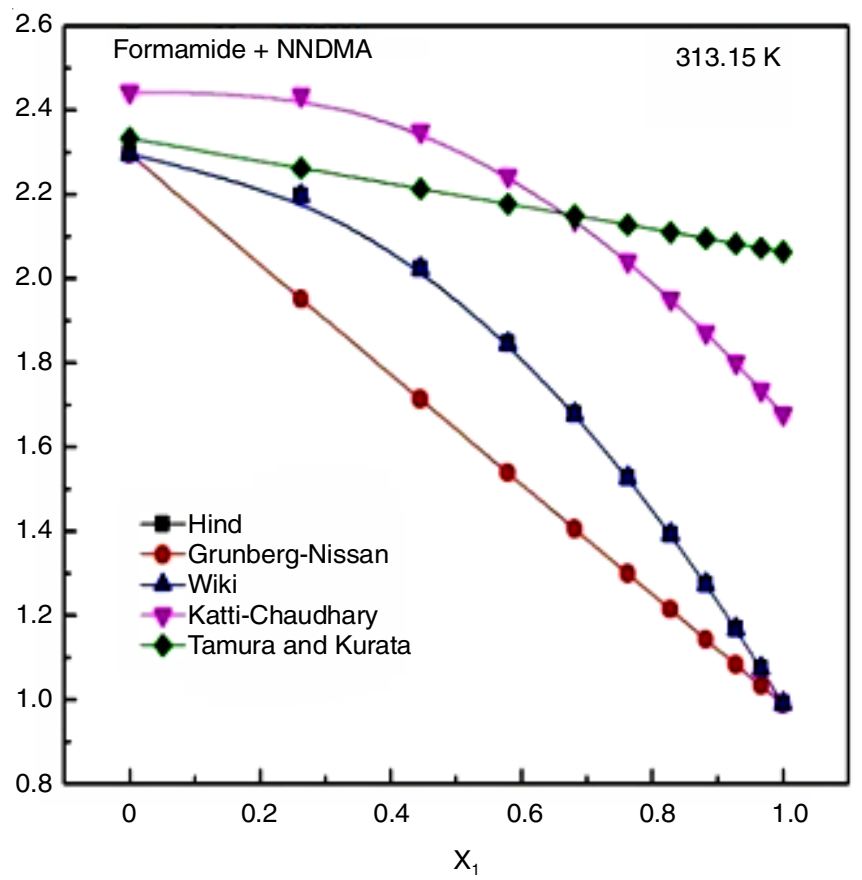

Fig. 6. Variation of viscosity theories with respect to mole fraction at $313.15 \mathrm{~K}$

bonds in the associates. And the higher values of standard deviation at $313.15 \mathrm{~K}$ (Fig. 6) indicates the maximum departure of particular theory from experiment at particular concentration, which determines the overall validity of the theory.

\section{Conclusion}

The computed speed of sound and viscosity values from different theories have been correlated with the experimentally measured values. Speed of sound values obtained from Nomoto's and Junjie's method relations are in good agreement with the experimental values. It may be concluded that out of these theories, Nomoto's relation is best suited for the liquid mixtures under study. The chi square values also support this theory. The experimental viscosity values are also compared with the viscosity values obtained from different empirical relations and Hind, Grunberg and Nissan are in good agreement with the experimental values. The observed deviation of theoretical values of viscosity and speed of sound from the experimental values is attributed to the presence of intermolecular interactions.

\section{ACKNOWLEDGEMENTS}

One of the authors (SB) is thankful to Er. K. Satyanarayana, President, Dr. M. Ramamoorthy (Chancellor), Dr. L.S.S. Reddy (Vice-Chancellor), Prof. K.L. Narayana (Dean R\&D) and Prof. B. Jay Kumar Sing (Assoc. Dean, Sponsored and Internal Funded Research) of Koneru Lakshmaiah Education Foundation for providing the internal funding (Research project Ref: KLU/ IF/Jan-17/018/PHY004).

\section{CONFLICT OF INTEREST}

The authors declare that there is no conflict of interests regarding the publication of this article.

\section{REFERENCES}

1. B. Shaik, Int. J. Chemical Concepts, 1, 81 (2015).

2. S.S. Sastry, S. Babu, T. Vishwam and H.S. Tiong, J. Chem. Thermodyn., 68, 183 (2014);

https://doi.org/10.1016/j.jct.2013.09.005.

3. R. Vaidya, S. Karthiyayini and N.K. Millerjothi, Res. J. Chem. Sci., 5, 33 (2015).

4. Z. Begum, P.B. Sandhya Sri and C. Rambabu, ISRN Phys. Chem., Article ID 943429 (2012); https://doi.org/10.5402/2012/943429.

5. M. Rani, S. Gahlyan, A. Gaur and S. Maken, Chin. J. Chem. Eng., 23, 689 (2015);

https://doi.org/10.1016/j.cjche.2014.12.003.

6. S. Gahlyan, S. Verma, M. Rani and S. Maken, Korean Chem. Eng. Res., 55, 520 (2017);

https://doi.org/10.9713/kcer.2017.55.4.520.

7. A. Hossain, S. Roy and B.K. Dolui, J. Mol. Liq., 232, 332 (2017); https://doi.org/10.1016/j.molliq.2017.02.080.

8. G.R. Satyanarayana, K.B. Krishna, K. Sujatha and C. Rambabu, Der Pharm. Chem., 6, 158 (2014).

9. G. Manukonda, V. Ponneri, S. Kasibhatta and S. Sakamuri, Korean J. Chem. Eng., 30, 1131 (2013); https://doi.org/10.1007/s11814-013-0014-y.

10. P.B. Sandhya Sri, Z. Begum and C. Rambabu, Phys. Chem.: An Indian J., 9, 57 (2014).

11. R.K. Shukla, A. Kumar, U. Srivastava, K. Srivastava and V.K. Pandey, Int. J. Thermophys., 37, 90 (2016); https://doi.org/10.1007/s10765-016-2096-3.

12. S. Velmourougane and T.K. Nambinarayanan, Indian J. Phys., 61B, 105 (1987).

13. M. Gowrisankar, P. Venkateswarlu, K.S. Kumar and S. Sivarambabu, J. Ind. Eng. Chem., 20, 405 (2014); https://doi.org/10.1016/j.jiec.2013.04.035.

14. S.V.K. Sastry, S. Babu, H.S. Tiong and S.S. Sastry, J. Chem. Pharm. Res., 4, 2122 (2012). 